\title{
Nas tramas do discurso da reforma do ensino médio: acontecimento, ideologia e memória
}

\author{
Maria do Socorro Aguiar de Oliveira Cavalcante ${ }^{1}$
}

\begin{abstract}
Taking as referential the assumed methodological theory of the Discourse Analysis based on the dialectic historical materialism, and, taking in Pêcheux (1997a, p. 92) which "all discursive process subscribes in a class based ideological relationship", we shall aim, in this paper, to uncover the discursive dimensions in which the recent educational reforms configures. Specifically in which concerns the perspective of the thinking and the projection of the educational policies of the neoliberal State. We elected as analysis object the discursive materiality in the project of Law $827 / 201$ that concerns another High School reform and that is causing controversies, in the environment of educators concerned with the directions of Brazilian education. We shall study the discourse and the significant materiality, historically produced, problematizing the senses in which it crosses and gives sustentation to the institutional speech, identifying the assumed position by the subjects.
\end{abstract}

Keywords: Discourse; high school; ideology; subject positions.

Resumo: Tomando como referencial os pressupostos teórico metodológicos da Análise do Discurso ancorada no materialismo histórico dialético, e, assumindo com Pêcheux (1997a, p. 92) que, "todo processo discursivo se inscreve numa relação ideológica de classe", buscaremos, neste trabalho, desvendar as dimensões discursivas que configuram a retórica das atuais reformas da educação, especificamente, no que concerne à perspectiva do Estado neoliberal de pensar e projetar as políticas educacionais. Elegemos como objeto de análise a materialidade discursiva do Projeto de Lei 867/201 que trata de mais uma reforma do Ensino Médio e tem causado polêmicas, no âmbito de educadores comprometidos com os rumos da educação brasileira. Estudaremos o discurso e sua materialidade significante, historicamente produzida, problematizando os sentidos que o atravessam e dão sustentação ao discurso institucional, identificando a posição assumida pelos sujeitos.

Palavras chave: Discurso; Ensino Médio; ideologia; posições de sujeitos.

Introdução

Este estudo resulta de investigações desenvolvidas no Grupo de estudos Políticas públicas: história e discurso do Programa de Pós Graduação do Centro de Educação da Universidade Federal de Alagoas e tem como objetivo apresentar reflexões acerca de um

1 Professora associada da Universidade Federal de Alagoas, graduada em Letras, com Mestrado e Doutorado em Letras e Linguística. Atua nos programas de Mestrado e Doutorado em Letras e Linguística. É líder do grupo de estudos em Políticas públicas: história e discurso - GEPPHED - e pesquisadora do Grupo de Estudos Discurso e Ontologia Marxiana - GEDOM. 
acontecimento que se discursivisa materializado na medida provisória 746/2016, convertida no Projeto de Lei 34/2016, aos quais se somam a portaria do Ministério da Educação $n^{\circ} 1145 / 2016$ e o Projeto de Lei 867/201 que trata da reforma do Ensino Médio e tem causado indignação, no âmbito de educadores comprometidos com os rumos da educação brasileira. Logo, uma reforma, em si, não é sinônimo de progresso; pode ser sinônimo de retrocesso.

É necessário, pois desvendar essas dimensões discursivas que configuram a retórica das atuais reformas, especificamente, no que concerne à perspectiva do Estado neoliberal de pensar e projetar as políticas educacionais. Vale lembrar, que, segundo Hengels (2009), é no contexto da divisão de sociedade em classes e da posse da propriedade que surge o Estado com a função de controlar e dominar determinados grupos em detrimento de outros, e, uma das formas de assegurar o controle desses grupos é através da educação.

Tomamos aqui a definição de acontecimento de Bakhtin (2017, p. 54), como "evento de curta ou longa duração, em seu contexto imediato, convocando uma memória histórica das tensões, no espaço de luta de classes". (Grifo nosso). O referido autor (idem) define evento como "movimento responsavelmente consciente da consciência que transforma a possibilidade na atualidade de uma ação realizada". Pêcheux (2006, p. 17), em sua obra $O$ discurso estrutura ou acontecimento, diz: "o acontecimento é o ponto de encontro entre uma atualidade e uma memória". Vale destacar como, em épocas diferentes, os dois autores, em suas definições, convocam a relação práxis (acontecimento). A esse respeito, também se posiciona Zandwais $(2015$, p. 1). Segundo a referida autora:

[...] para ler o acontecimento, é necessário convocar os sujeitos, pois se a memória evoca a história, ela somente se concretiza a partir do modo como são simbolizados na consciência dos sujeitos e, por fim discursivizados, acontecimentos diversos que se tornam objetos de diferentes leituras, $[\ldots]$ e, até mesmo de interpretações controversas.

Essas considerações levantadas de forma bastante superficial nos levam ao entendimento de que para analisar qualquer materialidade discursiva, há que se buscar o acontecimento histórico social que possibilitou sua objetivação. Entendido como práxis dos homens, em determinada conjuntura social e política, o discurso não nasce de psiquismo individual; ele emerge, a partir de acontecimentos, numa dada sociedade, produzindo sentidos historicamente determinados, que não resultam de propriedades linguísticas nem de puros arranjos sintáticos, mas como diz Pêcheux (1997a, p. 258), “dependem de um 'exterior' bem diferente que é o conjunto de efeitos, na 'esfera ideológica', da luta de classes, nas diversas formas: econômicas, políticas e ideológicas.”. Assim, como diz Silva Sobrinho (2010, p. 255): "é das contradições sócio históricas que brota a natureza conservadora ou transformadora de todo discurso".

Por essa razão, o estudo dos processos de produção de sentidos, na perspectiva do Materialismo histórico dialético, exige uma compreensão da sociedade na qual os discursos emergem, uma vez que são constituídos a partir de acontecimentos, numa dada sociedade, produzindo sentidos historicamente determinados. Também a esse respeito, de forma apropriada, afirma Courtine (2009, p. 163): "se não se tem o saber histórico que permite compreender profundamente a complexidade do objeto estudado, não se compreende nada de nada”. (Grifo nosso). Consequentemente, no estudo de qualquer materialidade discursiva, há que se levar em consideração o momento histórico da produção do discurso e a memória que ele convoca, pois é no jogo contraditório entre atualidade e 
memória no qual se realiza a articulação entre língua, história e memória que se constitui a historicidade do discurso. Por isso, ante qualquer materialidade discursiva, é necessário considerar suas condições de produção, ou seja, é preciso analisar a conjuntura histórica, política e social das relações sociais em que os sujeitos se movimentam, pois, só quando articulamos o dizer com suas condições de produção é que as contradições do discurso desvelam a face de suas contradições. (SILVA SOBRINHO, 2010).

Desde essa ótica, neste estudo, como já dissemos anteriormente, nosso objetivo é analisar como emergem, e que sentidos produzem os processos discursivos materializados em enunciados que circulam sobre mais uma reforma do Ensino Médio, no governo Temer.

\section{"Novo Ensino Médio"?}

Ante a intenção explicitada anteriormente, colocamos algumas questões que buscaremos responder neste trabalho. O que há de "novo"? na tão propalada reforma do Ensino Médio. Por que a referida reforma contempla apenas um nível de ensino da educação básica - o Médio? - Quais seus objetivos (não declarados)? Que sentidos obscurece e que memória convoca? Na perspectiva da $\mathrm{AD}$, para responder essas questões, temos de iniciar pelas condições de produção desse discurso. Como já dito em Cavalcante e Melo (2015, p. 71), "todo processo de produção discursiva surge a partir de um acontecimento, de uma conjuntura histórica, de um embate político que possibilita sua irrupção". Ao tratar da categoria Condições de Produção, é necessário concebê-la em dois sentidos: amplo e restrito. Para situar as condições de produção amplas, do discurso da reforma do Ensino Médio, trazemos Silva Sobrinho (2010, p. 258) que afirma: as condições de produção do discurso compreendem:

[...] a sociedade capitalista, em suas contradições, baseada na exploração dos homens pelos próprios homens que, para assegurar essa dominação exerce sobre os sujeitos um poder material de exploração do trabalho, e também espiritual, ao difundir um conjunto de ideias, valores, anseios e temores.

Assim, no modo de produção capitalista, os blocos de poder da classe dominante, ao longo da história, têm utilizado vários mecanismos para incrementar a produção e concretizar a "subsunção real do trabalho ao capital" (SANTOS E SILVA, 2017). Nesse âmbito, para manter o nível de acumulação do capital em níveis sempre crescentes, é preciso aprofundar a exploração da força de trabalho. Esse aprofundamento ocorreu após a revolução industrial mediante três formas de organização da produção: taylorismo, fordismo e toyotismo. Para assegurar essa última forma de organização, o neoliberalismo surge como perspectiva teórica e passa a constituir-se uma alternativa vigorosa para o modelo de acumulação capitalista que começa a mostrar seus sinais de esgotamento já na década 60, atingindo seu auge na década de 70 .

O neoliberalismo surge então como um processo de construção de hegemonia, que se implementa, segundo Gentile (1998), em dois sentidos: por um lado, através de um conjunto de reformas no plano econômico, político, jurídico, educacional e por outro, através de uma série de estratégias orientadas para impor novos sentidos, a partir dos quais seria possível legitimar as referidas reformas como únicas possíveis de serem implementadas. Essas estratégias se expressam na capacidade de impor os interesses do capital como verdades que devem ser defendidas por qualquer pessoa "medianamente sensata e res- 
ponsável". Nesse contexto, cabe ao Estado, como um dos "pilares inelimináveis do capitalismo" (MÉSZÁROS, 2015, captar as necessidades imanentes à reprodução do capital e implementar políticas com vistas ao atendimento dessas necessidades.

No âmbito estrito das condições de produção do discurso da reforma do Ensino Médio, temos de levar em consideração o Estado brasileiro e a forma como planeja e implementa políticas de educação, que, segundo Rummert (2015, p. 7), "nunca tiveram como horizonte a construção da emancipação humana"; ao contrário, as referidas políticas têm sempre um caráter compensatório, dualista e exclusivo.

Se fizermos um percurso da colônia aos dias atuais, podemos constatar que sempre predominou a dualidade com relação à educação destinada à elite e a destinada à classe trabalhadora. Segundo Ciavatta e Ramos (2011, p. 28):

No caso do ensino médio e da educação profissional, essa visão dual ou fragmentada se expressa, historicamente, desde a Colônia, pela reprodução das relações de desigualdade entre as classes sociais, na separação entre a educação geral, como preparação para os estudos superiores, e a preparação imediata para o mercado de trabalho, funcional às exigências produtivas.

Não é nossa pretensão fazer uma exposição desse percurso; apenas tomaremos alguns momentos históricos que marcaram as diversas mudanças pelas quais passou esse grau de ensino. Tomando com marco a década de 30, quando o Ensino Médio foi regulamentado por lei, já é possível perceber as disputas políticas pela definição do sentido e dos propósitos desse grau de escolaridade. Segundo Ramos (2006, p. 60), essa disputa “foi orientada por interesses de classes mediadas pelas características do desenvolvimento da economia capitalista em nosso país".

Assim, criaram-se dois sistemas de ensino independentes. Um caracterizado pelo caráter enciclopédico dos currículos, de caráter elitista, preparatório para o ensino superior e outro profissional restrito à configuração produtiva e ocupacional. (RAMOS, 2006). Esse caráter propedêutico foi acentuado na reforma Capanema em 1942, que fortaleceu o ensino privado. Diz a referida autora (idem, p. 64):

[...] A Lei Orgânica do Ensino Médio (1942), promulgada durante o Estado Novo, na gestão do Ministro Gustavo Capanema, acentuava a velha tradição do ensino secundário acadêmico, propedêutico e aristocrático. Predominava a função propedêutica voltada para o ensino superior, sob a égide da Constituição (1937) que fortaleceu o ensino privado.

Após o golpe militar de 1964, sob grande influência norte-americana, através de acordos assinados com a USAID ${ }^{2}$ e com o Conselho de cooperação técnica da Aliança para o Progresso, foi elaborado o Plano Estratégico de Desenvolvimento (1967), no qual, segundo Machado (2006, p. 53), uma das linhas de ação era:

[...] dar prioridade à preparação de recursos humanos para atender aos programas de desenvolvimento nos diversos setores, adequando o sistema educacional às crescentes necessidades do país, principalmente no que se refere à formação de mão de obra qualificada.

Isso ocorre exatamente no momento em que o movimento estudantil saía às ruas, reivindicando reformas nas universidades, visando democratizar seu acesso às classes traba-

2 United States Aid International Development. 
lhadoras. Na contramão dessas reivindicações, foi imposta a LDB 5692 de agosto de 1971 que estabelece a obrigatoriedade do segundo grau profissionalizante, sob o argumento de oferecer aos alunos das classes subalternas a possibilidade de ingresso no mercado de trabalho, após a conclusão do segundo grau. Essa obrigatoriedade, no entanto, é imposta apenas às escolas públicas. As escolas privadas mantiveram o ensino propedêutico, se fortaleceram e se ampliaram. Ou seja, o que se pretendeu com a obrigatoriedade do segundo grau profissionalizante nas escolas públicas, que não dispunham de instalações nem de professores capacitados para tanto, foi impedir (ou dificultar mais ainda) o acesso ao ensino superior público a alunos provenientes da escola pública.

Com a promulgação da Constituição de 1988, iniciam-se os debates para a elaboração de uma nova LDB que culminou com a vitória conservadora resultando na LEI "minimalista"3 9.394/96. Sob uma (nem tão) nova roupagem, a referida lei reedita, segundo Frigotto (1999, p. 24), "o economicismo, o tecnicismo e o produtivismo das reformas educativas patrocinadas pelo golpe militar, pós 64". Mediante um novo padrão de sociabilidade capitalista caracterizado pela desregulamentação da economia e pela flexibilização das relações e dos direitos sociais, a tônica do Ensino Médio foi "preparar para a empregabilidade". Ou seja, desenvolver competências genéricas e flexíveis para que as pessoas pudessem se adaptar às vicissitudes da realidade contemporânea.

Atualmente, no governo Temer, após 22 anos de implementação da nova LDB, que prescreve "que o Ensino Médio é a última etapa da Educação Básica e tem como objetivo a consolidação e aprofundamento dos conhecimentos adquiridos no Ensino Fundamental, sendo também responsável por possibilitar a continuação dos estudos", o governo atual sanciona o Projeto de Lei 867/201 que trata de mais uma reforma do Ensino Médio e tem causado polêmicas, no âmbito de educadores comprometidos com os rumos da educação brasileira. É a partir dessas reflexões, que passamos à análise de materialidades discursivas de propagandas que têm circulado na mídia, no intuito de convencer a sociedade de que a referida reforma vai atender aos anseios de todos.

\section{O discurso sobre a reforma do "novo" Ensino Médio}

Como já foi dito anteriormente, sendo um fenômeno que se dá sempre no âmbito das relações sociais, o objeto último da educação é a sociedade e seu objetivo, a conservação ou transformação de determinado modelo, de acordo com a correlação de forças políticas, em permanente confronto no seio dessa mesma sociedade. Assim sendo, a classe social que detém o poder político, através do Estado, sempre utiliza a educação no sentido de realizar (pelo menos em parte) seus objetivos. (CAVALCANTE, 2007). Diante dessas considerações e face às materialidades que elegemos, colocamos algumas questões que guiarão nossa análise. De que posições o sujeito enuncia? Que sentidos obscurece? Que se põe de novo e/ou se conserva nesse discurso?

Vejamos, a seguir, duas materialidades discursivas extraídas da propaganda do MEC, exibida na televisão, em que aparecem professores e alunos sorridentes defendendo a reforma.

Na primeira sequência, destaca-se a fala da professora.

Melhorar a educação dos jovens é uma das tarefas mais importantes e urgentes no Brasil. É pra ontem!

O novo Ensino Médio vai dar liberdade para você escolher as áreas de conhecimento de acordo com sua vocação e projeto de vida. Ou ainda optar pela formação técnica, caso

3 Termo atribuído por Florestan Fernandes. 
queira concluir o ensino e começar a trabalhar.

Agora, é você quem define seu futuro. (Grifo nosso).

Em seguida, a fala do aluno.

\begin{abstract}
E aí galera?
Vocês já conhecem o Novo Ensino Médio? Essa proposta que todo mundo está comentando por aí. Sabia que ela foi baseada na experiência de vários países? Países que tratam a educação como prioridade. E que ela vai deixar o aprendizado muito mais estimulante $e$ compativel com a realidade dos jovens de hoje?

Pois é! Agora, além de aprender o conteúdo obrigatório, essencial para a formação de todos [...] eu vou ter liberdade de escolher entre quatro áreas de conhecimento para me aprofundar. Tudo de acordo com a minha vocação e com o que eu quero para minha vida. E para quem prefere terminar o ensino já preparado para começar a trabalhar, poderá optar por uma formação técnica profissional, com aulas teóricas e práticas.

Agora, é você quem decide seu futuro. (Grifos nossos).
\end{abstract}

Confrontando as materialidades apresentadas, percebe-se que ambas enfatizam o caráter do novo na referida reforma, a liberdade de escolha do aluno “de acordo com sua vocação e projeto de vida” e a responsabilização do aluno por seu futuro: "agora, é você quem decide seu futuro".

É oportuno trazer aqui Mariani (2018, p. 37) que, ao falar sobre sua experiência inicial com a $\mathrm{AD}$, externa sua emoção ante a descoberta de "que o ideológico estava inscrito na ordem material da língua, inscrito no posicionamento dos advérbios, nas ausências de sujeito em orações com formas apassivadas etc. $\mathrm{O}$ ideológico não era um conteúdo, tinha sua materialidade na língua". (Grifo nosso). Ou seja, não há discurso neutro ou inocente, como também não são neutras as escolhas lexicais que engendram uma materialidade discursiva. $\mathrm{O}$ funcionamento da língua não é, pois alheio à práxis discursiva; possibilita deslocamentos e condensações, metáforas, metonímias, estabelecendo um jogo discursivo que procura encobrir o que o sujeito tem a ilusão de não revelar.

Assim, ao escolher o dêitico temporal agora, em "agora, você é quem decide seu futuro", autoriza-se a leitura de outro texto implícito: "antes, você não podia; não lhe era assegurado esse direito"; a proposta anterior é velha, ultrapassada, antidemocrática. (Agora é o “novo”). Além disso, convoca-se o sujeito a assumir o protagonismo do seu futuro: "você é que decide seu futuro"; "o novo Ensino Médio vai dar liberdade para você escolher as áreas de conhecimento de acordo com sua vocação e projeto de vida"; "eu vou ter liberdade de escolher entre quatro áreas de conhecimento para me aprofundar. Tudo de acordo com a minha vocação e com o que eu quero para minha vida." Enfatiza-se aí o discurso da liberdade de escolha e da autonomia. Ao induzir o estudante a acreditar que pode fazer as escolhas que quiser, produz-se a ilusão de que basta querer e se esforçar para conquistar o que se quer, apagando-se, com isso as diferenças de classe, as desigualdades sociais. Na sequência: "eu vou ter liberdade de escolher entre quatro áreas de conhecimento para me aprofundar” acena-se com a liberdade de escolha para aprofundamento entre as quatro áreas de conhecimento que são: linguagens, matemática, ciências da natureza e ciências humanas. Aprofundar o quê, se o aluno sequer conclui a educação básica? Com isso, camufla-se a fragmentação do processo de formação do aluno, além de silenciar que ele "terá liberdade de escolher" dentro das limitações que a realidade da escola pública oferece, pois silencia-se também que as escolas e os professores não estão preparados para implantar essa reforma 
Percebe-se, nessas discursividades, a materialização do discurso do individualismo, do fim das classes sociais, em que o indivíduo pode tudo, basta querer. É nesse sentido que Pêcheux (2014) afirma que o funcionamento da ideologia burguesa de exaltação à autonomia aprisiona todos os aspectos da subjetividade, inclusive o discursivo. Com isso, busca-se apagar a luta de classes, a exploração do homem pelo homem, as limitações impostas por uma sociedade desigual, fazendo com que os sujeitos se acreditem "livres" para "decidir seu futuro".

Também está patente nas materialidades discursivas a recuperação de elementos de saber da memória discursiva da pedagogia liberal em suas vertentes escolanovista e tecnicista. As escolhas do aluno serão de acordo com sua "vocação e projeto de vida". Retoma-se aí o discurso do dom, da vocação. Esse é um pressuposto da Escola Nova cuja função é preparar o aluno para assumir papeis na sociedade, de acordo com suas aptidões, respeitando as "diferenças individuais". Mais importante do que aprender é aprender a aprender. Nessa perspectiva, não existem desigualdades; apenas diferenças. Na pedagogia tecnicista, prevalece o aprender a fazer, ou seja, a função da escola é preparar mão de obra, isto é fornecer ao aluno um conhecimento básico, técnico para assumir uma função na rede de divisão social do trabalho.

Como diz Pêcheux (1997a, p. 92), "todo processo discursivo se inscreve numa relação ideológica de classe". Assim, os sujeitos assumem posições relacionadas às posições de classe, consequentemente, o discurso expressa posições assumidas pelos sujeitos em diferentes práticas sociais concretas. Desde essa ótica, ante a análise das materialidades em estudo, pode-se afirmar que os sujeitos do discurso da reforma do Ensino Médio assumem a perspectiva do capital. Referindo-se à referida reforma, Frigotto e Ramos $(2018$, p. 35) assim se expressam:

[...] trata-se de um ataque desferido contra as últimas conquistas do Ensino Médio na perspectiva da formação [...] dos jovens brasileiros. Retoma-se, de forma regressiva, princípios da Reforma Capanema dos anos de 1940 e das Leis n. 5692/1971 e 7044/1982. [...] Tais medidas do passado e do presente correspondem, no plano da cultura ao movimento da economia marcada pela contradição capital e trabalho.

É, pois no sentido de adequar a educação da classe trabalhadora às necessidades imanentes à reprodução do capital, que o Estado, sendo um dos pilares inelimináveis do sistema capitalista, implanta a referida reforma cujos objetivos (não declarados) são: favorecer o aligeiramento, a fragmentação, oferecendo uma educação com um mínimo de conteúdo que impeça o conhecimento do real, impedindo os estudantes de terem acesso aos bens científicos e culturais produzidos pela humanidade.

\section{Finalizando temporariamente}

Ante o exposto, é possível perceber que o funcionamento da língua não é alheio à práxis discursiva, pois que, como já dito anteriormente, o ideológico está inscrito na ordem material da língua, inscrito nas escolhas lexicais, nos posicionamentos dos advérbios, nas ausências de sujeitos o que possibilita deslocamentos, metáforas, estabelecendo um jogo discursivo que procura encobrir o que o sujeito tem a ilusão de não revelar. Assim, ao atribuir ao atual ensino médio a qualificação de novo, silencia-se o retorno ao velho - escolanovismo e tecnicismo -; silencia-se a prevalência do caráter dual, sempre presente nas 
reformas da educação profissional que separa a educação propedêutica, como preparação para as elites para os estudos superiores e uma formação profissional fragmentada e aligeirada para a classe trabalhadora. Com isso, a reforma do "novo" ensino médio interdita à classe trabalhadora o aceso ao conhecimento científico historicamente produzido; interdita o acesso aos instrumentos de leitura da realidade, interditando o futuro desses jovens.

É preciso, pois ter clareza de que a educação é um processo fundado no trabalho, que depende da economia e é gerida pelo Estado que busca administrar as crises do capital. Nesse sentido, um Estado bem gerido, na perspectiva do capital, tem de manter dois sistemas de educação - um para a elite e outro para a classe trabalhadora - pois inserida numa sociedade contraditória, a educação é determinada pelas contradições internas dessa sociedade. Ao fazer essa afirmação, não estamos pensando a educação apenas como reprodução dos interesses da classe dominante. Essa determinação não se dá de forma unidirecional, mas como diz Saviani (2002, p. 95) de forma "relativa e na forma de ação recíproca - o que significa que o determinado também reage sobre o determinante", pois a educação não se resume à transmissão de conhecimentos; não se resume a ideias pedagógicas; é práxis social; é ação de sujeitos. Assim, toda ação educativa é essencialmente política, pois tem uma intencionalidade e não se dá num vazio conceitual, mas sim direcionada por um modelo teórico de sociedade, tendo por objetivo sua manutenção ou conservação.

Assumindo com Pêcheux (1997a) o entendimento de que conhecimento científico e prática política não estão dissociados; ao contrário, são domínios essencialmente articulados, esperamos, com a Análise do Discurso que fizemos, contribuir para a compreensão do real e para a busca de possibilidades de intervenção.

\section{Referências}

BAKHTIN, M. Para uma filosofia do ato responsável. São Paulo: Pedro e João, 2017. CAVALCANTE, M. do S. A. de O. Qualidade e cidadania nas reformas da educação brasileira: o simulacro de um discurso modernizador. Maceió: EDUFAL, 2007. CAVALCANTE, M. do S. A. O; MACHADO, F. D. “O rugido das ruas" em 15 de março de 2015, no Brasil: acontecimento, discurso e memória. In: ZANDWAIS, A.; RASIA, G. dos S. (Org.). História das ideias: diálogo entre linguagem, sociedade e história. Revista Organon, v. 30, n. 59, 2015, p. 117-135.

CAVALCANTE M. do S. A. de O; MELO, K. M. S. O discurso sobre a instrução pública em Alagoas: história, memória e processos de ressignificação. In: CIAVATTA, M; RAMOS, M. N. Ensino Médio e Educação Profissional no Brasil. Dualidade e fragmentação, Revista Retratos da Escola, Brasília, v. 5, n. 8, jan./jun. 2011, p. 27-41. Disponível em: <http//www.esforce.org.br>. Acesso em: 27 mar. 2018. CAVAlCANTE, M. dos S. A. O; SANTOS, I. M. dos. (Org.). História e política da educação: teoria e práticas. Maceió: EDUFAL, 2015, p. 64-84.

COURTINE, J. J. Análise do discurso político o discurso comunista endereçado aos cristãos. São Carlos: Edufscar, 2009.

FRIGOTTO, G. A educação e formação técnico-profissional, frente à escola cidadã no contexto da Globalização. Petrópolis: Editora Vozes, 1999.

FRIGOTTO, G.; RAMOS, M. N. Medida provisória 746/2016: a contra reforma do ensino médio do golpe de estado de 31 de agosto de 2016. Revista HISTEDBR (on-line), Campinas, 2018. Disponível em: <https://periódicos.sbu.unicamp.br/ojs/index.php/ histedbr/index>. Acesso em: 27 mar. 2018. 
GENTILE, P. A desordem neoliberal, a violência do mercado e o destino da educação das maiorias. In: GENTILI, P. (Org.). Pedagogia da exclusão. Crítica ao neoliberalismo em educação. Petrópolis: Vozes, 1988, p. 228-252.

HENGELS, F. A origem da família, da propriedade privada e do estado. São Paulo: Escala Educacional, 2009.

MACHADO, L. R. Concepção de escola, de escola unitária e de politecnia. In: ITERRA - Instituto Técnico de Educação e Pesquisa da Reforma Agrária - Unidade de Educação Superior (Org.). Educação básica de Ensino Médio nas áreas de reforma agrária. Textos de estudos. São Paulo: ITERRA, 2006, p. 41- 50.

. Formação de professores para a educação profissional e tecnológica:

perspectivas históricas e desafios contemporâneos. Educação superior em debates, Brasília, MEC/INEP, v. 8, 2008.

MARIANI, B. O discurso que nos uniu. Para Eni Orlandi. Revista Traços de linguagem, Cáceres, v. 2, 2018.

MÉSZÁROS, I. A montanha que precisamos conquistar. São Paulo: BOITEMPO, 2015. PÊCHEUX, M. Análise Automática do Discurso, (AAD-69). In: GADET, F.; HAK, T. (Org.). Por Análise Automática do Discurso. Uma introdução à obra de Michel Pêcheux. 3. ed. Campinas: Editora da Unicamp, 1997a.

. O discurso estrutura ou acontecimento. Campinas: São Paulo: Pontes, 2006. . Semântica e discurso. Uma crítica à afirmação do óbvio. Campinas: Editora UNICAMP, 2014.

RAMOS, M. N. O Ensino Médio ao longo do século XX: um projeto inacabado. In: ITERRA - Instituto Técnico de Educação e Pesquisa da Reforma Agrária - Unidade de Educação Superior (Org.). Educação básica de Ensino Médio nas áreas de reforma agrária. Textos de estudos. São Paulo: ITERRA, 2006, p. 51-60.

RUMMERT, S. M. Prefácio. In: CAVALCANTE, M. do S. A. de O.; SANTOS, I. M. dos (Org.). História e política da educação: teoria e práticas. Maceió: EDUFAL, 2015, p. 7-18.

SANTOS, S. C. M. dos; SILVA, J. M. da. O projeto de educação da classe trabalhadora na sociedade capitalista: uma análise crítica no cenário brasileiro. In: NOMERIANO, A. S. et. al. As politicas educacionais no contexto dos limites absolutos do estado e do capital em crise. Maceió: EDUFAL, 2017, p. 161-178.

SAVIANI, D. Pedagogia histórico crítica: primeiras aproximações. São Paulo: Autores associados, 2002.

SILVA SOBRINHO, H. F. A.D. Um olhar materialista sobre as evidências de sentido. In: SILVA, L. R.; FREITAG, M. K. (Org.). Revista Linguagem e representação discursiva outros estudos, João Pessoa: Editora Universitária da UFPB, 2010, p. 247273.

ZANDWAIS, A. Contribuições de teorias de vertente marxista para os estudos da linguagem. Revista Conexão Letras, [S.1.], v. 9, n. 12, abr. 2015, p. 51- 63.

Recebido em: 23/04/2018 Aceito em: 18/06/2018. 